\title{
NOVOS ARRANJOS FAMILIARES E HOMOPARENTALIDADE: UMA APRECIAÇÃO DO JOGO DA VIDA "FAMÍLIAS MODERNAS"
}

\author{
NEW FAMILY ARRANGEMENTS AND HOMOPARENTALITY: AN APPRECIATION \\ OF THE GAME OF LIFE “MODERN FAMILIES”
}

\author{
Everton Ribeiro \\ Doutor em Educação \\ Instituto Federal do Paraná - IFPR. \\ Curitiba, Paraná - Brasil. \\ everton.ribeiro@ifpr.edu.br \\ Marcos Antunes Hoffmann Nunes \\ Mestre em Psicologia \\ Instituto Federal do Paraná - IFPR. \\ Jacarezinho, Paraná - Brasil. \\ marcos.nunes@ifpr.edu.br \\ Araci Asinelli-Luz \\ Doutora em Educação \\ Universidade Federal do Paraná - UFPR. \\ Curitiba, Paraná - Brasil. \\ araciasinelli@hotmail.com
}

\begin{abstract}
Resumo: Apesar da compreensão de que os arranjos familiares no Brasil têm mudado, inclusive por dados do último Censo Demográfico (IBGE, 2010), a legislação brasileira ainda é muito ambígua e tendenciosa em sua interpretação ao atribuir conceitualmente à entidade familiar como sendo a convivência duradoura, pública e contínua, de um homem e uma mulher, estabelecida com objetivo de constituição de família. Desta forma, qualquer concepção que fuja deste padrão estabelece uma dificuldade de se conceber enquanto família por fugir do convencional estereótipo 'comercial de margarina'. O não reconhecimento conduz à exclusão e, consequentemente, à violação dos direitos humanos, marginalizando e estabelecendo uma condição de subalternidade a casais que não correspondem à norma instituída. Deste modo, este trabalho propõe-se a realizar uma análise sobre a representação e performatividade de outras entidades familiares abordadas numa edição do Jogo da Vida - jogo de tabuleiro da Estrela - chamada "Famílias Modernas". No jogo, além da família tradicional, as entidades familiares gay, filho adotivo, independente e filho de divorciados estão presentes nas possibilidades de desenvolvimento de uma pessoa ao longo de sua vida pessoal e profissional. Sendo assim, intentamos analisar em que medida este jogo contribui para o respeito à diversidade, às novas formações familiares e à quebra de padrões e estereótipos perpetuados pela mídia acerca de indivíduos homossexuais ou aqueles que, simplesmente, não têm vontade de manter uma relação estável com outra pessoa.
\end{abstract}

Palavras-chave: Discriminação. Família. Performatividade. Representações sociais. Sexualidade.

Abstract: Despite the understanding that family structures in Brazil have changed, including recent data of Brazilian Institute of Geography and Statistics (IBGE, 2010), legislation from Brazil is still very ambiguous and biased in its interpretation by assigning conceptually to the family entity as the lasting, public and continuous coexistence of a man and a woman, established for the purpose of family formation. In this way, any conception that escapes this pattern establishes a difficulty to conceive as family by avoiding the convention of the "margarine commercial" stereotype. Non-recognition leads to the exclusion and, consequently, to the violation of human rights, marginalizing and establishing a condition of subordination to couples who do not correspond to the norm established. Thus, this work proposes to perform an analysis on the representation and performativity of other familiar entities addressed in an edition of "The Game of Life" - board game of the Estrela - called Modern Families. In addition to the traditional family, gay family adoptive child, independent and child of divorced parents are present in a person's development possibilities throughout their personal and professional lives. Thus, we try to analyze the extent to which this game contributes to respect for diversity, new family formations and the breaking of patterns and stereotypes perpetuated by the media about homosexual individuals or those who simply do not want to maintain a stable relationship with another person.

Keywords: Discrimination. Family. Performativity. Social Representations. Sexuality.

Para citar - (ABNT NBR 6023:2018)

RIBEIRO, Everton; NUNES, Marcos Antunes Hoffmann; ASINELLI-LUZ, Araci. Novos arranjos familiares e homoparentalidade: uma apreciação do jogo da vida "famílias modernas". Eccos - Revista Científica, São Paulo, n. 56, p. 1-11, e11452, jan./mar. 2021. Disponível em: https://doi.org/10.5585/eccos.n56.11452. 


\section{Preliminares}

Estamos vivenciando no mundo, em especial no Brasil, uma onda de conservadorismo bastante assustadora nos últimos anos. Talvez ela sempre tenha existido, latente em alguns espaços, mas, ao ocupar as cadeiras do Congresso Nacional, a onda foi invadindo a praia e tomando proporções alarmantes regidas por uma narrativa que se diz preocupada com a família tradicional brasileira e com a proteção das crianças. A onda começou a passar por cima de tudo que, segundo ela, desrespeita a moral e bons costumes. Nem que para isso tivessem que agir com imoralidade e desrespeito aos direitos humanos. Retrocederam, no âmbito político, debates importantes para a garantia dos direitos humanos, tais como: a descriminalização do aborto, a criminalização da homofobia, a retirada do termo gênero e diversidade sexual do currículo escolar e de documentos importantes como o PNE (Plano Nacional de Educação) e os PMEs (Planos Municipais de Educação), debate sobre o suicídio no âmbito da saúde pública, o casamento civil igualitário, a adoção de crianças por casais homoafetivos, o projeto "escola sem partido" e, não menos importante, a elaboração de um "estatuto da família" que não reconhece outras possibilidades, além da família tradicional constituída por pai, mãe e filhos.

Este último documento, aprovado por uma Comissão Especial vinculada à Câmara dos Deputados, busca decretar que entidade familiar é "o núcleo social formado a partir da união entre um homem e uma mulher, por meio de casamento ou união estável" (BRASIL, 2013, art. $2^{\circ}$, grifo do documento). A Constituição da República Federativa do Brasil de 1988 já estabelece o que é considerado entidade familiar, por isso fica clara que a preocupação do projeto de lei é desqualificar arranjos familiares que fogem à heteronormatividade e, por isso, impedir que o Supremo Tribunal Federal aplique o entendimento jurídico de que casais homoafetivos também são considerados uma família e, logo, têm os mesmos direitos de se casarem em um cartório, além de acesso à seguridade social e pensão. O Estatuto da Família é uma reação aos direitos dos indivíduos cuja orientação sexual não é heterossexual, desprezando o princípio da igualdade, pelo qual deveria prezar toda e qualquer legislação. Torna-se, pois, uma tentativa de se opor aos direitos de pessoas Lésbicas, Gays, Bissexuais, Transgêneros, Intersexuais e Queer (LGBTIQ). Sabemos que este projeto de lei é reflexo da imposição de valores religiosos ${ }^{1}$, os quais não deveriam interferir na organização do Estado, especialmente ratificado por sua laicidade.

${ }^{1}$ No Brasil, existe uma frente parlamentar conservadora conhecida popularmente como "bancada evangélica", que reúne diversos políticos de partidos diferentes que se articulam contra temas relacionados à diversidade sexual, à igualdade de gênero e à democracia racial. 
É importante lembrar que o próprio Censo Demográfico 2010, realizado no Brasil pelo IBGE, apresenta resultados bastante diversificados para a constituição de famílias. Considerando pluralidade em sua classificação, a amostra revela novos arranjos familiares: unipessoal, casal sem filhos, casal com filhos, monoparental feminina, monoparental masculina, entre outros. O documento, em sua análise, ainda constata que:

\begin{abstract}
Os arranjos familiares são menos tradicionais, cresce o número de uniões consensuais e, com o aumento dos divórcios, há também um crescimento significativo das famílias reconstituídas, nas quais os filhos podem ser apenas de um dos cônjuges. Outro efeito conhecido das separações e dos divórcios é o aumento do número de crianças que crescem em famílias monoparentais (BRASIL, 2012, p. 64).
\end{abstract}

Deste modo, considerando a importância da análise demográfica para a criação de políticas públicas que atendam às demandas populacionais, está evidenciado que a proposta do Estatuto da Família está desalinhada em relação ao perfil das famílias brasileiras das últimas décadas. Por isso, é verossímil que o teor do documento nada tem a ver com "a valorização e apoiamento à entidade familiar" (BRASIL, 2013, art. 1. ${ }^{\circ}$ ), mas com a perpetuação de valores machistas, heteronormativos e sexistas, portanto, discriminatórios.

Apesar de um cenário político e social bastante desanimador, ainda podemos ter esperanças e reconhecer que já tivemos muitos avanços, embora as ondas conservadoras invistam esforços para desmontar as conquistas e retroceder. Graças aos esforços de movimentos de mulheres alinhados a outros movimentos sociais, ao longo da história, é possível perceber tensionamentos no status quo, no sentido de desestabilizar a ordem hegemônica. Podemos entender que as lutas feministas e a crescente inserção da mulher nos espaços sociais provocaram uma mudança significativa na forma de a sociedade se organizar, bem como nas relações estabelecidas entre homens e mulheres. Vivemos o que Castells (2010) concebe como crise da família patriarcal em que a autoridade do homem se vê diminuída. Podemos perceber isso por meio do modelo tradicional de família que se mostra fragilizado, cedendo lugar para outros arranjos familiares: unipessoal, casal sem filhos, casal com filhos, monoparental feminina e monoparental masculina, por exemplo. Em conformidade com Dias (2010, p. 22), “o conceito de família migrou da genitalidade para a afetividade”. Os vínculos familiares já não são mais marcados pela relação consanguínea, mas pelo afeto. 


\section{Arranjos familiares: pontos de análise}

Viajávamos em junho de 2017, durante o feriado, para Salvador, quando começamos a ler a revista de bordo de uma companhia aérea brasileira, cuja reportagem de capa foi “Álbum de família - filhos, trabalho e casamento: tudo junto e misturado na vida do casal Fabio Souza e Alexandre Herchcovitch" (LACOMBE, 2017). Apenas com a manchete já sentimos uma emoção surpreendente pela visibilidade dada a um novo arranjo familiar, que se torna cada vez mais invisibilizado em nossa sociedade. Já havíamos notado, há algum tempo, que aquela companhia aérea respeita e manifesta a diversidade nas publicações de sua revista. Nesta matéria, especialmente, discute-se parentalidade e homoafetividade, dois temas bastante controversos devido ao desserviço promovido pela falaciosa ideologia de gênero, que atribui relações forjadas entre homossexualidade, abuso sexual e pedofilia, por exemplo. Na verdade, existe, sim, uma ideologia de gênero: a heteronormativa. A que eles pregam e esperam que todos correspondam a ela deliberadamente. Ainda sobre a ideologia de gênero Jimena Furlani abordou em entrevista online à "Pública":

[...] as cartas não estão na mesa, eles não assumem que ninguém está doutrinando crianças na escola, que eles querem que não se fale de gênero na escola para que as crianças não acolham os sujeitos da diversidade, para que não aceitem que as pessoas possam ser vistas definitivamente sem preconceito. Que eles não aceitam os direitos humanos ampliados [...] (FURLANI, 2017).

Apesar de existirem novos arranjos familiares e pleitos de adoção por casais homoafetivos, a invisibilidade destas famílias é reforçadora dos processos de discriminação. No espaço escolar, por exemplo, não é incomum a realização de eventos comemorativos do Dia das Mães e do Dia dos Pais - datas puramente comerciais, diga-se de passagem. Este tipo de atividade enfatiza os estereótipos familiares, além de ser excludente. Algumas escolas têm optado pela comemoração do Dia da Família - ampliando a leitura das diferentes estruturas familiares -, o que parece mais inclusivo e respeitoso. Neste caso, é de extrema importância o cuidado para não perpetuar o arranjo familiar que se julga mais apropriado ou tomado como referência. Portanto, seria mais adequado comemorar o Dia das Famílias, considerando sua pluralidade. A escola pode ser um espaço privilegiado para a visibilização da diferença e do acolhimento à diversidade. 
[...] a forma como a instituição de ensino acolheu a família homoparental de Chicão, filho biológico de Cássia Eller e de sua companheira Maria Eugênia, parece-nos exemplar. $\mathrm{O}$ debate público em torno da homossexualidade veio à tona em 2002 , quando da disputa da guarda de Chicão entre Maria Eugênia, reconhecida publicamente como mãe social e cuidadora do menino, e seu avô materno, pai de Cássia. Chicão então estudava em uma escola de classe média, no Rio de Janeiro, considerada de esquerda. Familiares, docentes e estudantes da escola mobilizaram-se em favor de Eugênia, companheira da cantora. Acredita-se que o apoio institucional, com adesão a um manifesto encaminhado ao juiz responsável pelo processo, tenha sido importante para o desenrolar do caso (MELLO; GROSSI; UZIEL, 2009, p. 174).

Porém, no cotidiano, observamos uma realidade bastante diferente quanto ao acolhimento e respeito às diferenças. Se a escola, por um lado, se legitima como lugar de conhecimento, por outro, torna-se lugar de ocultamento e apagamento em relação a algumas temáticas como, por exemplo, as sexualidades de pessoas que vivenciam outros modos de expressão. Estes apagamentos terão desdobramentos nocivos no que se refere ao reconhecimento dos direitos civis, como, por exemplo, o casamento e o exercício da parentalidade, de sujeitos que apresentam sexualidades dissidentes.

A escola é, sem dúvida, um dos espaços mais difíceis para que alguém "assuma" sua
condição de homossexual ou bissexual. Com a suposição de que só pode haver um
tipo de desejo sexual e que esse tipo - inato a todos - deve ter como alvo um
indivíduo do sexo oposto, a escola nega e ignora a homossexualidade
(provavelmente nega porque ignora) e, desta forma, oferece muito poucas
oportunidades para que adolescentes ou adultos assumam, sem culpa ou vergonha,
seus desejos. O lugar do conhecimento mantém-se, com relação à sexualidade, como
o lugar do desconhecimento e da ignorância (LOURO, 2013, p. 30).

Neste ínterim, a partir da urgência em visibilizar as novas configurações familiares, achamos muito intrigante a existência de um jogo que apresenta novas famílias - modernas em sua proposta educativa. A concepção do brinquedo está preocupada com a atualidade, com o fato de ser "mais parecido à sua vida. Seja ela como for" (JOGO DA VIDA FAMÍLIAS MODERNAS, 2011). Deste modo, interessamo-nos em perceber a representação social que o jogo faz destes novos arranjos familiares, bem como a performatividade destes papéis socialmente. Assim, faremos a descrição de alguns pontos abordados no jogo - especialmente a contraposição entre uma família tradicional e uma família gay - para gerar discussão e análise sobre suas representações.

A escolha por esta contraposição não deve ser vista de forma arbitrária ou tendenciosa. A verdade é que a família homoparental ainda não possui legitimidade enquanto arranjo familiar, apesar de amparo legal. A Arguição de Descumprimento de Preceito Fundamental 132 do Rio de Janeiro (ADPF n. 132 RJ) e a Ação Direta de Inconstitucionalidade 427 (ADI n. 4277), analisadas e votadas pelo Supremo Tribunal Federal, em 2011, decidiram, por 
unanimidade, pela obrigatoriedade do reconhecimento como entidade familiar a união entre pessoas do mesmo sexo. A relatoria, no entanto, é bastante densa e complexa. Ela se sustenta por questões fundamentais de uma sociedade democrática, da dignidade da pessoa humana e compreende a homossexualidade como "fato da vida [...] que não viola qualquer norma jurídica, nem é capaz, por si só, de afetar a vida de terceiros” (BRASIL, 2011). No entanto, nem a homossexualidade, tampouco a união estável de pessoas do mesmo sexo, são representadas à luz da sociedade de direitos, como uma família "daquelas de propaganda".

\title{
3 Jogo da vida: famílias modernas
}

O Jogo da Vida Famílias Modernas é uma edição exclusiva limitada de um jogo de tabuleiro inspirado no original Jogo da Vida - também fabricado pela Estrela - sob responsabilidade da marca Nebacetin (Laboratório Nycomed), no ano de 2011. O marketing do jogo está na proposta da diversidade de famílias que compõem a atualidade, cujo slogan é "As famílias mudam. O jeito de cuidar não". Veja a introdução do jogo expressa em seu manual:

\begin{abstract}
As famílias mudam. Por isso, nada mais justo do que poder jogar com uma família parecida com a sua. Então, conheça os personagens e escolha o seu. Depois, experimente os outros perfis também. Você vai descobrir que, apesar das diferenças, a diversão é sempre a mesma (JOGO DA VIDA FAMÍLIAS MODERNAS, 2011).
\end{abstract}

Basicamente, a diferença do Jogo da Vida Famílias Modernas para o original da Estrela é a pluralidade de arranjos familiares (tradicional, gay, filho adotivo, independente, filho de divorciados). No entanto, há um dado bastante peculiar em comparação aos dois jogos: a classificação etária. Enquanto o tabuleiro original da Estrela é recomendado para crianças a partir de 8 anos, o jogo idealizado pela marca Nebacetin é classificado para adultos a partir de 19 anos. Entramos em contato com a Estrela por meio de e-mail para tomar conhecimento dos critérios que determinaram a faixa etária do Jogo da Vida Famílias Modernas. O retorno que obtivemos foi de que a faixa etária do brinquedo foi determinada pela indústria farmacêutica e de que só eles poderiam conceder maiores informações. Em contato com a Nycomed - atualmente administrada pela Takeda Distribuidora - não recebemos resposta.

Com a análise do conteúdo do jogo, constatamos que não há nada que impeça que crianças e adolescentes brinquem com o tabuleiro. Porventura, presumimos que a única censura ao jogo seja a leitura conservadora de seus idealizadores de que crianças não estão 
preparadas para compreender e refletir acerca de sexualidade. Ou melhor, de uma sexualidade dissidente, que as faça questionar a vigilância de corpos a qual estamos expostos cotidianamente. Infelizmente, esta leitura não é nada incomum.

Eles defendem o poder de educar os filhos dentro da norma sexual e de gênero, como princípios heterossexuais. Eles desfilam para conservar o direito de discriminar, castigar e corrigir qualquer forma de dissidência ou desvio, mas também para lembrar aos pais dos filhos não-heterossexuais que o seu dever é ter vergonha deles, rejeitá-los e corrigi-los (PRECIADO, 2013).

Em síntese, o Jogo da Vida Famílias Modernas apresenta as mesmas regras do jogo original; logo, poderia ser jogado, também, por crianças a partir de 8 anos.

O jogo tem 24 cartas família. Estas cartas ficam embaralhadas em um monte e são reveladas quando algum dos participantes cai na casa "CARTA FAMÍLIA" correspondente no tabuleiro. Em cada uma delas, há um texto com instruções específicas de acordo com um dos cinco arranjos familiares escolhido pelo jogador. $\mathrm{O}$ foco deste trabalho é criar pontos de análise acerca de homossexualidade e família. Por isso, daremos maior enfoque à família gay, em contraponto à família tradicional, com base nas descrições das cartas instrutivas e tendo em vista que o principal alvo do grupo que defende o estatuto da família é a homoparentalidade.

A família gay é representada pelo pino rosa e a família tradicional pelo pino azul. A escolha por essas cores estabelece um estereótipo evidente. Não bastassem as cores, cada pino é descrito no manual para auxiliar na escolha da personagem que você vai jogar. Veja as descrições dos cinco arranjos familiares:

Tradicional - pino azul

Imagine uma família daquelas de propaganda: papai, mamãe, filhinhos. Com o personagem Tradicional, essa vida é realidade para você.

Gay - pino rosa

Sorte no jogo, sorte no amor: escolha o Gay se você acredita na liberdade para escolher também quem vai te acompanhar pelo caminho.

Filho Adotivo - pino laranja

Viva com o Filho Adotivo as situações de quem não nasceu naquela família, mas hoje está mais em casa do que nunca.

Independente - pino verde

O Independente é aquele que resolveu cuidar de si mesmo. Escolha esse personagem para avançar muito bem acompanhado, mesmo que sozinho.

Filho de Divorciados - pino roxo

Quer saber o que acontece quando o casal segue trilhos diferentes? Então escolha o Filho de Divorciados, que vê os pais longe, mas com o mesmo carinho.

(JOGO DA VIDA FAMÍLIAS MODERNAS, 2011). 
Só nesta descrição já encontramos alguns aspectos para reflexão: a parentalidade está relegada à família nuclear? Um outro arranjo familiar diferente do tradicional não pode ser representado numa propaganda? Um indivíduo heterossexual não tem sorte no amor e/ou não está livre para escolher seu par?

Com estas descrições, podemos inferir que o jogo reproduz estereótipos da orientação sexual de cada indivíduo. Vejamos algumas instruções ${ }^{2}$ das cartas família que contribuem para este argumento:

\footnotetext{
Gay

Comprou um presente de Dia dos Namorados.
}

Crise no namoro. Mas não fique triste: agora você pode adicionar aquela paquera no seu perfil da internet.

Um amigo abriu uma nova boate e você tem de prestigiar.

Aquela pessoa que você achava que era hétero é gay. Pague e leve ao cinema.

Show da sua diva no Brasil. Imperdível.

Seu look saiu em um blog de moda.

Ganhou um bilhetinho de admirador secreto.

(JOGO DA VIDA FAMÍLIAS MODERNAS, 2011).

A representação da família gay no jogo é a de uma pessoa solteira e independente apesar de já existir uma família com esta especificidade. Pouco se atribui a ela possibilidade de um relacionamento estável. Pelo contrário, ao gay é imputado consumismo exagerado, promiscuidade, futilidade, infidelidade e instabilidade nas relações afetivas. Apresenta-se a ideia mercadológica de que gays têm maior poder aquisitivo, desfrutam mais de atividades de lazer e, consequentemente, não constituem uma família parental.

\begin{abstract}
A questão, nesses casos, ainda fica muito associada - para alguns juízes e psicólogos também - a um estereótipo do homossexual masculino, como aquele que teria uma sexualidade incontrolada; fica como um fantasma do abuso sexual. (...) Alguns modos de existência não são legítimos e profissionais reafirmam isso em laudos, em pareceres, em práticas clínicas, em diferentes espaços (ZAMBRANO; MOURÃO; CASSAU, p. 120-125).
\end{abstract}

Por outro lado, a família tradicional é tida por preocupações coletivas, que expressam a participação na vida de outros membros do convívio familiar.

\footnotetext{
${ }^{2}$ Todas as instruções das cartas família são sucedidas por valores a pagar ou receber. Como estas informações são irrelevantes para a análise do material, foram suprimidas da citação.
} 


\section{Tradicional}

Contratou animadores para a festa das crianças.

O hamster do seu filho ganhou uma corrida.

As crianças pediram um pônei de Natal.

O sonho da casa própria tem um preço.

O novo carro da família é flex.

Você conseguiu um desconto na van que leva seus filhos pra escola.

Você sabe quantas fraldas um bebê gasta?

(JOGO DA VIDA FAMÍLIAS MODERNAS, 2011).

Além da coletividade, fica claro que a parentalidade é o grande foco da representação da família tradicional. A ela é atribuída estabilidade, contenção de gastos, economia doméstica e educação dos filhos. Pouco se faz referência à relação afetiva do casal, a atenção irrestrita está dedicada à prole, tanto do ponto de vista afetivo quanto do ponto de vista orçamentário.

\section{Algumas reflexões}

Apesar de reconhecermos o mérito e a importância do Jogo da Vida "Famílias Modernas", por abordar e problematizar diferentes configurações e arranjos familiares considerando as transformações sociais, culturais, políticas e econômicas -, o jogo pouco contribui para a superação de estereótipos difundidos pela mídia em geral, e em especial pela televisiva, sobre indivíduos homossexuais. Tampouco contribui para heterossexuais, uma vez que reafirma uma única forma de viver a sexualidade e exercer a parentalidade. É possível perceber que o jogo em questão ainda apresenta gêneros e sexualidades a partir de uma perspectiva binária e essencialista baseada em estereótipos arcaicos, reproduzindo discursos naturalizados e cristalizados que dificultam o reconhecimento de outros modos de existência. Não podemos desconsiderar o caráter mercadológico de um brinquedo - ou de qualquer outro artigo comercial - ao se apropriar de um tema contemporâneo, como a diversidade de famílias. Não obstante trazer a representatividade das diferenças em seu bojo, o jogo traz consigo muito do preconceito perpetuado nas relações sociais sobre a diversidade sexual. $\mathrm{Ou}$ seja, a busca pelo lucro se sobrepõe à quebra de paradigmas.

A família Souza-Herchcovitch não está representada na categoria de família gay. Nem a de Cássia Eller e Maria Eugênia. Poderíamos também considerar a ausência de representatividade de uma família lésbica, o que geraria outros pontos de tensão. 
Em suma, o que necessitamos é de visibilidade para novos arranjos familiares e de políticas públicas que amparem toda e qualquer constituição familiar. Enquanto identidade sexual for um critério para adoção sobreposto ao desenvolvimento de crianças e adolescentes órfãos, pouco avançaremos na equidade de direitos de todos os modos de existência. Enquanto perpetuarmos estereótipos de homossexuais - seja em um jogo educativo, seja em uma programação televisiva, seja em um evento escolar - estaremos cada vez mais distanciando-os da existência enquanto família: materializada apenas na capa de uma revista.

\section{Referências}

BRASIL. Ministério do Planejamento, Orçamento e Gestão. Censo demográfico 2010: famílias e domicílios: resultados da amostra. Rio de Janeiro: IBGE, 2012. Disponível em: . Acesso em: 18/07/2017.

BRASIL. Projeto de Lei 6.583, de 16 de outubro de 2013. Dispõe sobre o Estatuto da Família e dá outras providências. Câmara dos Deputados, Brasília, DF, 16 out. 2013. Disponível em: . Acesso em: 18/07/2017.

BRASIL. Ação Direta de Inconstitucionalidade n. 4277 e Arguição de Descumprimento de Preceito Fundamental n. 132/RJ. Supremo Tribunal Federal, Brasília, DF, 05 mai. 2011. Disponível em: . Acesso em: 11/04/2018.

CASTELLS, M. O poder da identidade. São Paulo: Paz e Terra, 2010.

DIAS, B. M. A união homoafetiva e a Constituição Federal. In: COSTA, Horácio Costa et al (Org.). Retratos do Brasil homossexual: fronteiras, subjetividades e desejos. São Paulo: Editora da Universidade de São Paulo: Imprensa Oficial, 2010. p. 22.

FURLANI, Jimena. Existe “ideologia de gênero"?. Pública, São Paulo, 30 ago. 2016. Disponível em: . Acesso em: 03/11/2017.

JOGO da vida família modernas. Itapira, SP: Estrela, 2011. 1 tabuleiro +1 roleta +160 pinos +8 carrinhos +56 cartas +360 notas em caixa.

LACOMBE, Milly. Lado a lado. Gol, São Paulo, ano 16, n. 183, p. 100-108, jun. 2017.

LOURO, G L. (Org.). O Corpo Educado: pedagogias da sexualidade. $3^{\text {a }}$ Ed. Belo Horizonte: Autêntica Editora, 2013.

MELLO, Luiz; GROSSI, Miriam; UZIEL, Anna Paula. A escola e @s filh@s de lésbicas e gays: reflexões sobre conjugalidade e parentalidade no Brasil. In: JUNQUEIRA, Rogério Diniz (org.). Diversidade sexual na educação: problematizações sobre a homofobia nas escolas. Brasília: Ministério da Educação, Secretaria de Educação Continuada, Alfabetização e Diversidade, UNESCO, 2009. p. 159-181. 
PRECIADO, Beatriz. Qui défend l'enfant queer?. Libération, Paris, 14 jan. 2013. Disponível em: . Acesso em: 20/07/2017.

ZAMBRANO, Elizabeth; MOURÃO, Janne Calhau; CASSAU, Luan Carpes Barros. Psicologia, sexualidade, novas configurações familiares e aspectos legais da promoção de direitos. In: Psicologia e diversidade sexual: desafios para uma sociedade de direitos. Brasília: Conselho Federal de Psicologia, 2011. p. 109-129. 